\title{
Axillary Reverse Mapping in Breast Cancer
}

\author{
Masakuni Noguchi, Miki Yokoi, \\ Yasuharu Nakano, Yukako Ohno and Takeo Kosaka \\ Kanazawa Medical University Hospital \\ Japan
}

\section{Introduction}

Axillary lymph node dissection represents the standard surgical treatment for breast cancer patients with clinically or histologically involved axillary lymph nodes. However, it is associated with significant morbidity, including postoperative arm lymphedema and neuropathy of the involved extremity, and seroma formation in the axilla (Noguchi et al., 1997). Particularly, arm lymphedema develops in $7 \%-77 \%$ of patients who undergo axillary lymph node dissection (Blanchard et al., 2003; Leidenius et al., 2005; Haid et al., 2002; Mansel et al., 2006; Ronka et al., 2005; Schijven et al., 2003; Schrenk et al., 2000; Swenson et al., 2002). At present, sentinel lymph node biopsy is accepted as the standard method of surgical staging for axillary lymph nodes in breast cancer. It can avoid unnecessary axillary lymph node dissection in node-negative patients, thereby minimizing arm lymphedema. Nevertheless, node-positive patients who undergo axillary lymph node dissection do not benefit from sentinel lymph node biopsy. Moreover, sentinel lymph node biopsy does not completely eliminate arm lymphedema. Several cooperative group trials have shown lymphedema rates in range of approximately $7 \%$ with sentinel lymph node biopsy alone (Sakorafas et al., 2006; Wilke et al., 2006).

Recently, the axillary reverse mapping technique has been developed to map and preserve arm lymphatic drainage during axillary lymph node dissection and/or sentinel lymph node biopsy (Nos et al., 2007; Thompson et al., 2007). This technique is based on the hypothesis that the lymphatic pathway from the arm cannot be involved by metastasis of the primary breast cancer. The assumption is that the lymphatic drainage from the upper arm is different from that of the breast, allowing safe removal of only the lymphatics of the breast and protection of the lymphatic channels draining the upper extremity during axillary lymph node dissection or sentinel lymph node biopsy, thereby preventing arm lymphedema. However, several studies have shown that there are limits to the principle of non-overlap between breast and arm nodes, including: (a) the axillary reverse mapping nodes may be involved with metastatic foci in patients with extensive axillary lymph node metastases (Bedrosian et al., 2010; Kang et al., 2009; Noguchi et al., 2010b; Nos et al., 2008; Ponzone et al., 2009), and (b) the sentinel lymph node draining the breast may be the same as the axillary reverse mapping node draining the upper extremity in some patients (Boneti et al., 2009; Britton et al., 2009; Kang et al., 2009; Noguchi et al., 2010b). Therefore, the oncological safety of this procedure has not yet determined. This article presents a review of current knowledge regarding in the axillary reverse mapping procedure, and discusses its practical applicability and relevance. 


\section{Lymph nodes and lymphatics from the breast and the upper extremity}

Knowledge of the lymphatic pathway from the breast tissue is essential for the diagnosis and treatment of axillary lymph node metastases in breast cancer. Sappey's classic studies of the lymphatic anatomy of the chest wall are familiar to most physicians (Sappey, 1874) (Fig. 1). Sappey distinguished a superficial group of lymphatics originating in the skin over the breast (subcutaneous lymphatics) and a deep group draining the mammary gland itself (intramammary lymphatics). The superficial and intramammary lymphatics anastomose extensively in the breast, and flow from the two lymphatic groups moves centrifugally toward the axillary and internal mammary nodes. Particularly, the axillary lymph nodes constitute the major regional drainage site for breast cancer. Sappey reported that the lymphatics of the breast collected in a subareolar plexus and then drained toward the axilla via lymph collecting vessels. Rouviere (1932), Grant et al. (1953), and Borgstein et al. (2000) supported Sappey's concept of the subareolar plexus for the breast lymph drainage. However, Turner-Warwick (1959), Spratt (1979), Tanis et al. (2001), and Suami et al. (2008) observed that lymphatic pathways from the breast drained directly into the axilla without first passing through the subareolar plexus. Thereby, two potential routes of lymphatic connections from the breast parenchyma to the axilla have been suggested: (a) direct lymphatic connections from the breast parenchyma to the axilla and (b) drainage of parenchyma via the subareolar complex into the axillary lymph nodes (Fig. 2) (Noguchi, 2009). This knowledge is important with regard to the optimal injection site for identifying sentinel lymph node in breast cancer, because subareolar injection may not always identify the same sentinel lymph node as peritumoral injection (Noguchi et al., 2009).

On the other hand, superficial and deep lymphatics from the upper extremity always flow into the axillary lymph node (called the "sentry node") (Fig. 3) (Suami et al., 2007a, 2007c).In the upper extremity, there is usually no communication between the superficial and deep lymphatics except in the epitrochlear region (Suami et al., 2007b). The superficial and deep lymphatics differ in that the former go straight to the axillary lymph nodes, whereas the

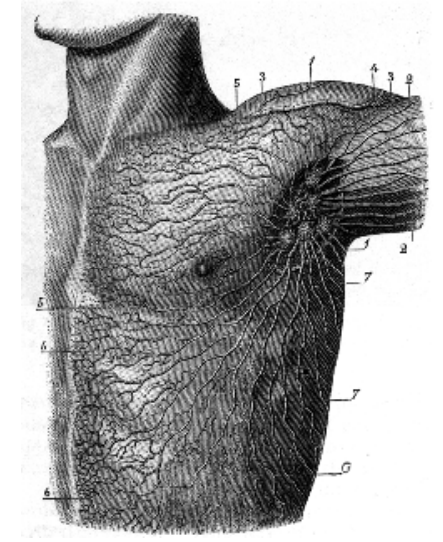

Fig. 1. Sappey's drawing of the superficial lymphatics of the upper torso. [Reprinted from Sappey, M.P.C. In A. Delahaye and E. Lecrosnier (Eds.), Anatomie, Physiologie, Pathologie des Vaisseaux Lymphatiques Consideres Chez l'Homme et Les Vertebres. Paris: Adrien Delahaye, 1874]. 
latter first pass through several interval lymph nodes before reaching the axilla. Thereafter, the lymphatics pass through several lymph nodes before merging into one vessel to reach the subclavian vein (Suami et al., 2007b). In the axilla, however, there are lymphatic interconnections between lymph nodes draining the upper extremity and nodes draining the breast (Suami et al., 2007a).

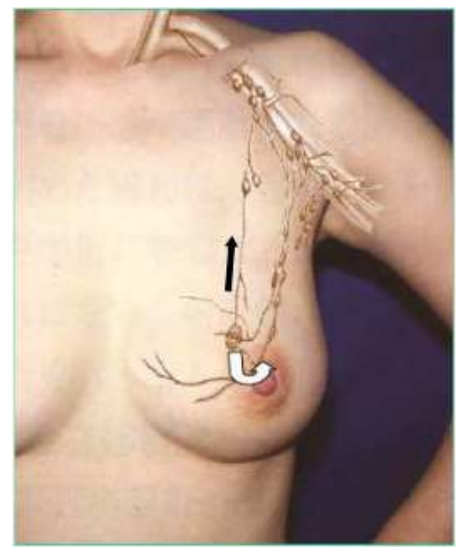

Fig. 2. Lymphatic flow from the breast tumor to the axilla. The black arrow shows a direct lymphatic connection from the breast parenchyma to the axilla and the white arrow shows drainage of the parenchyma via the subareolar complex into the axillary lymph nodes.
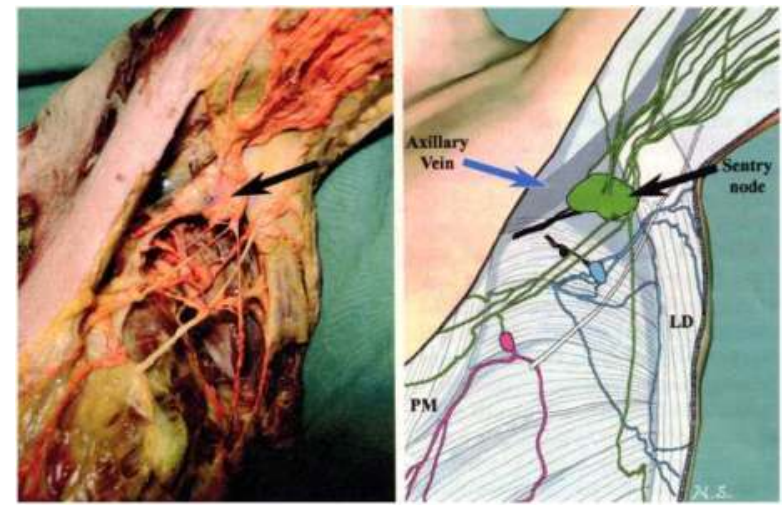

Fig. 3. Lymphatic anatomy in the axilla. Left: The left axilla region of the dissected male specimen; Right: a schematic diagram of the same area. The sentry node (black arrow) was connected with the lymphatics from both the upper limb and the upper torso (green). (Reprinted from Suami H: Plast Reconstr Surg 122: 1231-1239, 2008).

\section{Axillary reverse mapping}

The concept of axillary reverse mapping involves mapping the drainage of the arm with blue dye to determine the anatomical variation in these lymphatics and thus to provide a 
roadmap for their preservation (Klimberg, 2008). Five variations of axillary reverse mapping lymphatics have been identified: (1) above or below the axillary vein; (2) a sling pattern that may come as much as $4 \mathrm{~cm}$ below the axillary vein; (3) a lateral apron; (4) a medial apron; and (5) a twine of cord-like pattern of multiple small nodes. All of these usually emanate from the arm just lateral to the thoracodorsal vessels just under the axillary vein - the socalled axillary ring (Klimberg, 2010). Variations in arm lymphatic drainage put the arm lymphatics at risk for disruption during axillary lymph node dissection or sentinel lymph node biopsy. If arm lymphedema is caused by cutting axillary lymphatics, then being able to see and identify them would allow their preservation. In effect, "axillary reverse mapping is the reverse of sentinel lymph node mapping that serves to map and then remove the lymph nodes draining the breast; axillary reverse mapping involves mapping the arm drainage to allow its preservation" (Klimberg, 2008) (Fig. 4). This procedure is based on the hypothesis that the lymphatic pathway from the arm is not involved by metastasis of the primary breast cancer (Ponzone et al., 2008). However, the preservation of axillary reverse mapping nodes and/or lymphatics is not always possible, because oncological radicality with complete lymphatic preservation may be difficult (Ponzone et al., 2008).

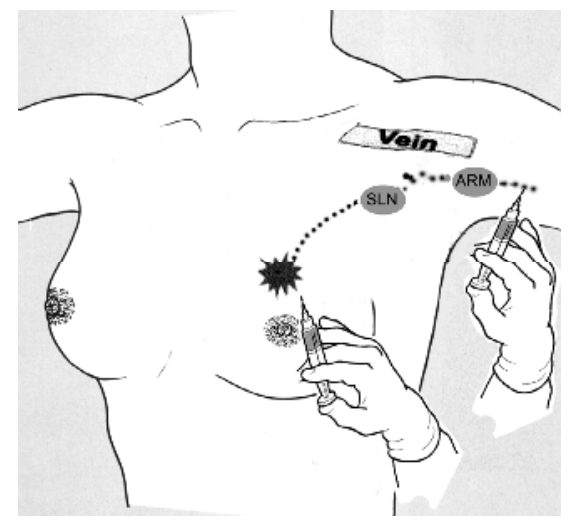

Fig. 4. Concept of axillary reverse mapping. Drainage from the breast sentinel lymph node and other lymph nodes from the breast rarely overlap with the lymphatics draining the arm. (Reprinted from Noguchi M : Breast Cancer Res Treat 119:529-535, 2010)

On the other hand, the extent of lymphatic channel disruption required to cause clinically significant lymphedema is unknown. However, it has been suggested that identification and preservation of axillary reverse mapping nodes and/or lymphatics are essential for decreasing postoperative lymphedema rates (Boneti et al., 2008). Boneti et al. (2008) observed the development of lymphedema in 2 of 12 patients in whom the axillary reverse mapping node and/or lymphatics were sacrificed, whereas no lymphedema occurred in patients in whom the axillary reverse mapping node was spared regardless of whether sentinel lymph node biopsy alone or axillary lymph node dissection was performed. In our previous study (Yokoi et al., submitted), 5 of 100 patients developed lymphedema after a mean follow-up of 8 months: 3 patients had undergone axillary lymph node dissection with removal of axillary reverse mapping nodes and lymphatics, and 2 patients had undergone sentinel lymph node biopsy with removal of axillary reverse mapping nodes because the SLN was the same as the axillary reverse mapping node. Although the follow-up has been 
short in this study, no lymphedema occurred in the remaining patients who had undergone sentinel lymph node biopsy without removal of axillary reverse mapping nodes. As prevention is the key to avoiding lymphedema (Boneti et al., 2008), preservation of axillary reverse mapping nodes and/or lymphatics is worthwhile. If axillary reverse mapping can be confirmed to be both safe and effective in preventing lymphedema, this technique will become the most important technological advancement since sentinel lymph node biopsy.

\section{Mapping of axillary reverse mapping node and lymphatics}

\subsection{Mapping by blue dye injection}

Several investigators have reported feasibility studies of the axillary reverse mapping procedure using blue dye (Fig. 5) (Boneti et al., 2008; Casabona et al., 2008, 2009; Nos et al., 2007; Ponzone et al., 2008; Thompson et al., 2007). Thompson et al. (2007) injected $2.5 \mathrm{~mL}$ of blue dye intradermally or subdermally into the upper inner arm along the medial intramuscular groove of the ipsilateral arm. After injection, the site was massaged and the arm elevated for $5 \mathrm{~min}$ to enhance arm lymphatic drainage. Consequently, blue lymphatics and/or nodes in relation to axillary reverse mapping were identified in 11 of 18 (61\%) patients, although no blue lymphatics or nodes were identified in the remaining 7 patients. In the same year, Nos et al. (2007) identified axillary reverse mapping nodes in 15 of 21 patients $(71 \%)$ using a similar technique. Subsequently, several investigators identified axillary reverse mapping nodes using blue dye (Boneti et al., 2008, Casabona et al., 2008; Casabona et al., 2009; Ponzone et al., 2008).

However, identification rates of axillary reverse mapping nodes using blue dye alone were insufficient, ranging from $61 \%$ to $86 \%$ (Boneti et al., 2008; Casabona et al., 2009; Nos et al., 2007; Ponzone et al., 2008; Thompson et al., 2007) (Table 1), and the blue staining at the injection site may persist for up to 6 months after injection (Thompson et al., 2007). To use axillary reverse mapping, moreover, surgeons must use only isotope in the breast to use blue dye in the arm (Klimberg, 2008). This would not be acceptable for those surgeons who believe that the blue dye and radioisotope techniques are complementary for identifying sentinel lymph nodes (Albertini et al., 1996; Noguchi et al., 2000; Noguchi et al., 2009).

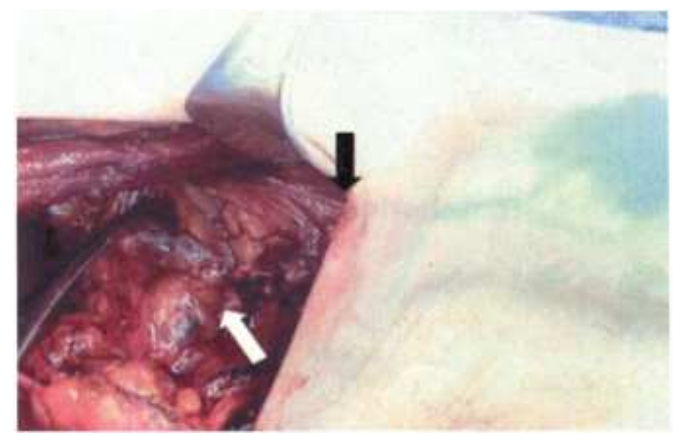

Fig. 5. Blue axillary reverse mapping lymphatic. The blue dye tattoo is shown on the inner aspect of the left upper arm in this patient. The white arrow shows a "lateral apron" of blue nodes well below the axillary vein, which is at the level of the black arrow (Reprinted from Klimberg VS: J Surg Oncol 97:563-564, 2008). 


\begin{tabular}{|c|c|c|c|}
\hline Method of ARM procedure & No. of ARM & Identification rates of ARM & Identification rates of ARM \\
\hline Authors/Years & procedures & (ALND field) & (SLN biopsy field) \\
\hline \multicolumn{4}{|l|}{ (a) Blue dye } \\
\hline Thompson et al. (2007) & 18 & Nodes/lymphatics: $61 \%(11 / 18)$ & l \\
\hline Nos et al. (2007) & 21 & Nodes: $71 \%(15 / 21)$ & 1 \\
\hline Ponzone et al.(2007) & 4 & Nodes/lymphatics: $50 \%(2 / 4)$ & l \\
\hline Boneti et al.(2008) & 131 & I & Lymphatics: $43 \%(56 / 131)$ \\
\hline Casabona et al.(2009) & 72 & Lymphatics: $89 \%(8 / 9)$. & Lymphatics: $38 \%(27 / 72)$ \\
\hline \multicolumn{4}{|l|}{ (b) Isotope } \\
\hline Nos et al. (2008) & 23 & Nodes: $91 \%(21 / 23)$ & 1 \\
\hline Britton et al.(2009) & 15 & Nodes: $100 \%(15 / 15)$ & / \\
\hline \multicolumn{4}{|l|}{ (c) Fluorescence } \\
\hline Noguchi et al. (2010b) & 20 & Nodes/lymphatics: $88 \%(7 / 8)$ & Nodes/lymphatics: $75 \%(9 / 12)$ \\
\hline Yokoi et al. (submitted) & 100 & Nodes: $93 \%(25 / 27)$ & Nodes: $37 \%(27 / 73)$ \\
\hline
\end{tabular}

Table 1. Results of Axillary Reverse Mapping Procedure

\subsection{Mapping by isotope injection}

To improve the identification rate of the axillary reverse mapping nodes and to prevent a persistent blue stain at the site of injection, Nos et al. (2008) injected an isotope into the web space of the ipsilateral hand. During axillary lymph node dissection, the radioactive axillary reverse mapping node was localized above the second intercostal brachial nerve, and then blue dye was injected directly into the node to visualize the efferent ducts constituting the lymphatic axillary reverse mapping chain. Consequently, the axillary reverse mapping nodes were identified in 21 of 23 patients (91\%) (Table 1). However, this procedure may be somewhat cumbersome and result in longer operating time. Moreover, direct injection into the axillary reverse mapping node using a syringe with high pressure may cause backflow into the sentinel lymph node, thereby increasing the rate of sentinel lymph node and axillary reverse mapping node confluence. On the other hand, Britton et al. (2009) injected 99mTc-human polyclonal immunoglobulin $G$ into the breast to identify the sentinel lymph node and injected 111In-human polyclonal immunoglobulin $\mathrm{G}$ into the hand to identify axillary reverse mapping nodes. In the specimen of axillary lymph node dissection, the axillary reverse mapping nodes were identified postoperatively in all of 15 patients $(100 \%)$ using a well scintillation counter (Table 1). Thus, radioisotope labeling seems to be more sensitive for detecting axillary reverse mapping nodes than use of blue dye alone. Identification rates of axillary reverse mapping nodes were improved by using radioisotope with or without blue dye (Britton et al., 2009; Nos et al., 2008). However, radioisotope alone does not permit the visual mapping of axillary reverse mapping lymphatics (Nos et al., 2008).

\subsection{Mapping by fluorescent imaging}

We have used an invisible near-infrared fluorescence imaging system (PhotoDynamic Eye; Hamamatsu Photonics, Hamamatsu, Japan) for identifying the axillary reverse mapping 
nodes and/or lymphatics (Figs. 6 \& 7) (Noguchi et al., 2010b; Yokoi et al., submitted). Before the surgical prep, a smaller volume of indocyanine green $(0.1 \mathrm{~mL}, 0.25 \mathrm{mg})$ (Diagnogreen; Daiichi Pharmaceutical, Tokyo, Japan) was injected into the forearm to decrease the risk of long-term tattooing, and the injection site was massaged until fluorescent axillary reverse mapping lymphatics were observed in the upper inner arm. During axillary lymph node dissection or sentinel lymph node biopsy, the light was occasionally switched off in the operating room and fluorescent axillary reverse mapping nodes and/or lymphatics were observed in the axilla using the fluorescence imaging system. Consequently, the axillary reverse mapping nodes were identified in $25(93 \%)$ of 27 patients who underwent axillary lymph node dissection alone (Yokoi et al., submitted) (Table 1). Although the fluorescent axillary reverse mapping nodes and/or lymphatics were not observed in 2 patients, they were early cases in the study (Noguchi et al., 2010b). Thus, the fluorescence imaging technique is useful for detecting lymphatic drainage from the upper extremity, and it also permits differentiation of fluorescent axillary reverse mapping nodes and/or lymphatics from blue and/or hot sentinel lymph nodes (Noguchi et al., 2009).

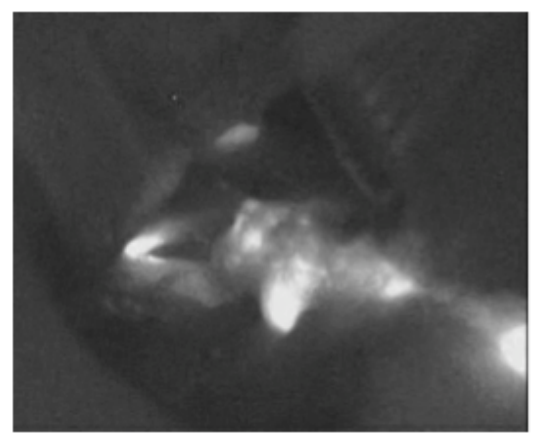

Fig. 6. Fluorescence imaging in the upper extremity.

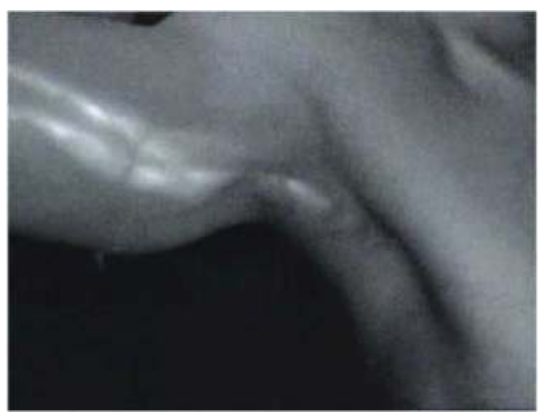

Fig. 7. Fluorescence imaging in the axilla.

\section{Mapping of axillary reverse mapping node and lymphatics in the fields of axillary lymph node dissection and sentinel lymph node biopsy}

Generally, identification of the axillary reverse mapping nodes is not sufficient in patients undergoing sentinel lymph node biopsy alone (Boneti et al., 2008; Casabona et al., 2009; 
Noguchi et al., 2010b). Boneti et al. (2008) reported that blue lymphatics draining the arm were visible from the sentinel lymph node biopsy incision, and so were located near or within the sentinel lymph node field in $56(42.7 \%)$ of 131 patients. Casabona et al. (2009) also reported the blue lymphatics draining from the arm in the sentinel lymph node biopsy field in 27 of 72 patients (37.5\%). Similarly, in our recent study, axillary reverse mapping nodes were identified in 27 (37\%) of 73 patients who underwent sentinel lymph node biopsy. In the remaining 46 patients, however, the axillary reverse mapping node was not observed in the sentinel lymph node field (Yokoi et al., submitted), suggesting that the ARM nodes were located in different fields with respect to the sentinel lymph node area. In these studies (Boneti et al., 2008; Casabona et al., 2009; Noguchi et al., 2010b; Yokoi et al., submitted), a difference was observed in the identification rate of axillary reverse mapping nodes and/or lymphatics in the axillary lymph node dissection field and in the sentinel lymph node field (Table 1). This may be because the majority of lymphatics draining the arm are anatomically located deeper than the sentinel lymph node (Casabona et al., 2009). This hypothesis is consistent with the higher incidence of lymphedema after axillary lymph node dissection than after sentinel lymph node biopsy (Celebioglu et al., 2007; Lucci et al., 2007; McLaughlin et al., 2008; Schrenk et al., 2000).

\section{Metastases in axillary reverse mapping nodes}

The concept of axillary reverse mapping is based on the hypothesis that the lymphatic pathway from the arm is not involved by metastasis of the primary breast cancer (Ponzone et al., 2008). Initial studies showed that no cancer cells were found in the ARM nodes even when the patients had many positive axillary nodes (Boneti et al., 2008; Casabona et al., 2009; Thompson et al., 2007) (Table 2). Subsequently, they preserved the axillary reverse mapping nodes in patients in the later series (Boneti et al., 2008; Thompson et al., 2007).

\begin{tabular}{|l|l|l|l|}
\hline Authors/references & No. of patients & $\begin{array}{l}\text { No. of patients with ARM } \\
\text { involvement }\end{array}$ & $\%$ of ARM involvement \\
\hline Thompson et al. (2007) & 7 & 0 & 0 \\
Nos et al. (2007) & 10 & 0 & $0 \%$ \\
Boneti et al. (2008) & 7 & 3 & $0 \%$ \\
Nos et al. (2008) & 21 & 3 & $14 \%$ \\
Ponzone et al. (2009) & 27 & 9 & $11 \%$ \\
Kang et al. (2009) & 101 & 2 & $8.9 \%$ \\
Bedrosian et al. (2010) & 11 & 3 & $18 \%$ \\
Noguchi et al. (2010) & 7 & 11 & $43 \%$ \\
Yokoi et al. (submitted) & 25 & & $44 \%$ \\
\hline
\end{tabular}

ARM: axillary reverse mapping

Table 2. The Involvement of Axillary Reverse Mapping Nodes in Patients who underwent Axillary Lymph Node Dissection with Removal of Axillary Reverse Mapping Nodes 
However, recent studies have demonstrated involvement rates of axillary reverse mapping node ranging from $8.9 \%$ to $44 \%$ (Table 2). In a study performed in France, Nos et al. (2008) reported that the axillary reverse mapping nodes showed metastatic involvement in 3 of 21 patients with N0-3 (14\%). Ponzone et al. (2009) also found that three patients with extensive nodal metastatic involvement (i.e., $\mathrm{pN} 2 \mathrm{a}$ and $\mathrm{pN} 3 \mathrm{a}$ ) showed metastatic cells in the axillary reverse mapping nodes, although the ARM was clear of metastases in the remaining 24 $(89 \%)$ of 27 patients. In a large study, Kang et al. (2009) reported that ARM node metastases were found in $9(8.9 \%)$ of 101 patients who underwent axillary reverse mapping procedure. In our recent study (Yokoi et al., submitted), on the other hand, the axillary reverse mapping nodes were positive in $11(44 \%)$ of 25 patients with a clinically positive node who underwent axillary lymph node dissection without sentinel lymph node biopsy. The fluorescence imaging system was highly sensitive for identification of the fluorescent axillary reverse mapping nodes, and the excised axillary reverse mapping nodes were cut into serial sections at $2 \mathrm{~mm}$ intervals for the histological examination (Noguchi et al., 2010b). This may increase the detection of metastatic axillary reverse mapping nodes. It is not surprising that the axillary reverse mapping nodes could be involved by metastasis of the primary breast cancer, because of anatomical interconnections between lymphatics draining from the upper extremity and lymphatics draining from the breast (Suami et al., 2007a). It has been suggested that effacement of nodes by the gross tumor may alter the pattern of lymph flow in these patients, allowing metastasis to the axillary reverse mapping nodes.

\section{Convergence of axillary reverse mapping node and sentinel lymph node}

The sentinel lymph node is most commonly located in the central nodal group, and it is possible that the axillary reverse mapping nodes are located in the central nodal group. If the sentinel lymph node draining the breast were the same node as the axillary reverse mapping node draining the upper extremity, it would be impossible to preserve the axillary reverse mapping node at sentinel lymph node biopsy. Boneti et al. (2009) reported that crossover (axillary reverse mapping node $=$ sentinel lymph node) occurred in only $6(2.2 \%)$ of 220 patients, although axillary reverse mapping lymphatics were near or within the sentinel lymph node biopsy field in $40.6 \%$ of patients. However, Britton et al. (2009) reported that sentinel lymph node from the breast was the same as the axillary reverse mapping node from the upper extremity in $2(13 \%)$ of 15 patients, indicating convergence of the two drainage pathways through the same node. Kang et al. (2009) also reported a concordance rate of $18.9 \%$ (19/96) between axillary reverse mapping node and sentinel lymph node. Noguchi et al. (2010b) reported that the sentinel lymph node from the breast was the same as the axillary reverse mapping node from the upper extremity in $3(21 \%)$ of 14 patients (Fig. 8). In our recent study (Yokoi et al., submitted), the sentinel lymph node from the breast was the same as the axillary reverse mapping node from the upper extremity in 20 of 27 patients in whom axillary reverse mapping nodes were identified, but the axillary reverse mapping node was not observed in the sentinel lymph node field in the remaining 46 patients, yielding a concordance rate of $27 \%(20 / 73)$ between axillary reverse mapping node and sentinel lymph node (Table 3). These findings were supported by a recent anatomical description of the lymphatic territories of the upper extremity (Suami et al., 2008). Removal of this common lymph node at sentinel lymph node biopsy will result in disruption of lymphatic drainage of the upper extremity and an increased risk of lymphedema, explaining why sentinel lymph node biopsy does not correct the problem of 
lymphedema (Schrenk et al., 2000; Sener et al., 2001; Wilke et al., 2006). This is an important limitation of the axillary reverse mapping procedure (Khan \& Lurie, 2009), although the axillary reverse mapping lymphatics vary significantly from patient to patient.
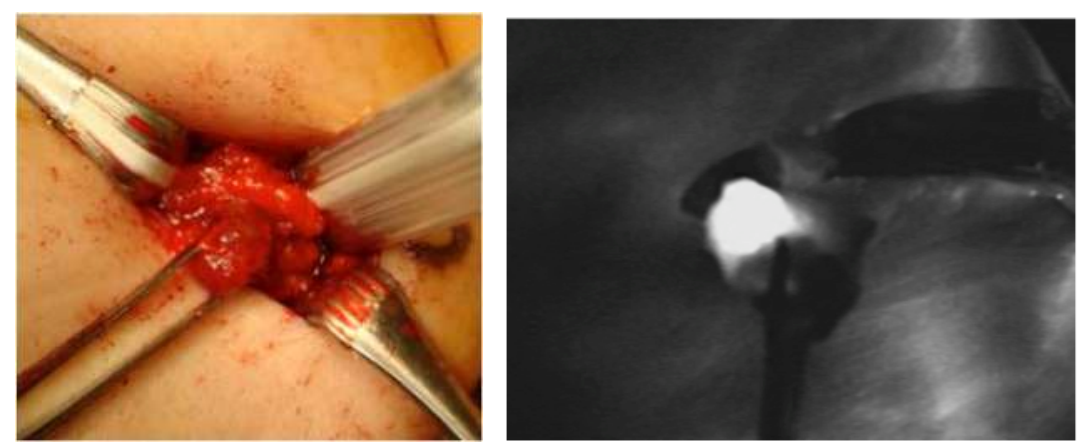

Fig. 8. Sentinel lymph node and axillary reverse mapping node. Left: sentinel lymph node biopsy: A hot and blue node was identified. Right: Fluorescence imaging by Photodynamic Eye: A fluorescent ARM node in the axilla, which is the same as the SLN.

\begin{tabular}{|llll|}
\hline Authors/references & $\begin{array}{l}\text { No. of } \\
\text { patients }\end{array}$ & $\begin{array}{l}\text { No. of patients with converged } \\
\text { sentinel lymph node - axillary } \\
\text { reverse mapping node }\end{array}$ & $\begin{array}{l}\text { Rates of } \\
\text { convergence } \\
(\%)\end{array}$ \\
\hline Boneti et al. (2009) & 220 & 6 & $2.2 \%$ \\
Britton et al. (2009) & 15 & 2 & $13 \%$ \\
Kang et al. (2009) & 96 & 19 & $18.9 \%$ \\
Noguchi et al. (2010) & 14 & 2 & $14 \%$ \\
$\begin{array}{l}\text { Yokoi et al. } \\
\text { (submitted)* }\end{array}$ & 73 & 20 & $27 \%$ \\
\hline
\end{tabular}

*: This study included patients from the previous study (Noguchi et al., 2010).

Table 3. Concordance of sentinel lymph node and axillary reverse mapping nodes in patients who underwent sentinel lymph node biopsy and axillary reverse mapping procedure.

\section{Preservation of axillary reverse mapping node and lymphatics}

Several studies have demonstrated that the axillary reverse mapping nodes are involved with metastatic foci in some patients with extensive axillary lymph node metastasis (Bedrosian et al., 2010; Kang et al., 2009; Noguchi et al., 2010; Nos et al., 2008; Ponzone et al., 2009; Yokoi et al., submitted). Therefore, patients with suspected extensive nodal disease at clinical examination, ultrasonography of the axilla, or intraoperative pathologic assessment 
should not be candidates for preservation of axillary reverse mapping nodes and lymphatics (Ponzone et al., 2009). On the other hand, the SLN draining the breast is the same node as the axillary reverse mapping node draining the upper extremity in some patients (Boneti et al., 2009; Britton et al., 2009; Kang et al., 2009; Noguchi et al., 2010; Yokoi et al., submitted). It is impossible to preserve converged sentinel lymph node - axillary reverse mapping node, although the excision of one converged node does not always translate into lymphedema, because multiple lymphatic channels drain the arm. Thus, there is no reliable separation of arm and breast lymphatic pathways, because there are lymphatic interconnections between lymph nodes draining the upper extremity and nodes draining the breast.

However, it has been suggested that patients with clinically uninvolved nodes might derive the most benefit from the axillary reverse mapping procedure (Ponzone et al., 2009). In a previous study by Boneti et al. (2009), 220 patients with clinically uninvolved nodes underwent sentinel lymph node biopsy and axillary reverse mapping procedure. Forty of these patients subsequently underwent axillary lymph node dissection because of positive sentinel lymph nodes. Consequently, axillary reverse mapping nodes were negative for malignancy. In our recent study (Yokoi et al., submitted), axillary reverse mapping node was identified in 27 of 73 patients with clinically uninvolved nodes who underwent sentinel lymph node biopsy, and it was the same as the sentinel lymph node in 20 patients. In 11 patients with a positive sentinel lymph node who subsequently underwent axillary lymph node dissection, however, axillary reverse mapping nodes were tumor-free as far as it was not the same as the positive sentinel lymph node. Therefore, it may be possible to spare the remaining axillary reverse mapping nodes during axillary lymph node dissection in patients with clinically negative node but positive sentinel lymph node.

To minimize prolonged seroma and prevent arm lymphedema, on the other hand, Kodama routinely performed lower axillary dissection without using either axillary reverse mapping or sentinel lymph node biopsy. The lower axillary dissection is defined as dissecting axillary lymph nodes only below the second intercostal brachial nerve. Consequently, they found that the 5-year overall and relapse-free survival rates were $95.3 \%$ and $88.3 \%$, respectively, in 1043 clinically node-negative patients from 2001 to 2008 (Kodama et al., 2010). They were not significantly different from those of 1084 clinically node-negative patients who underwent total or partial axillary lymph node dissection from 1994 to 2000 (94.9\% and 88.4\%, respectively). Only $6(0.6 \%)$ of 1043 patients developed axillary recurrence with a median follow-up of 72 months, while no lymphedema occurred. Although axillary reverse mapping nodes are usually localized above the second intercostal brachial nerve, therefore, it may be oncologically safe to spare axillary lymph nodes and lymphatics above the second intercostal brachial nerve in patients with clinically negative nodes. However, sentinel lymph node is not infrequently located above the second intercostal brachial nerve, and the axillary reverse mapping procedure is a more accurate means of preserving lymphatics from the upper extremity than partial axillary lymph node dissection. Therefore, sentinel lymph node biopsy followed by axillary lymph node dissection with axillary reverse mapping is oncologically more safe than the lower axillary dissection in patients with clinically negative nodes.

\section{Microsurgical lymphatic-venous anastomosis}

It is not always possible to preserve ARM nodes and/or lymphatics during axillary lymph node dissection or sentinel lymph node biopsy. Therefore, Casabona et al. $(2008,2009)$ 
performed microsurgical lymphatic-venous anastomosis using lymphatic collectors coming from the arm and one of the collateral branches of the axillary vein. Lymphatic collectors were introduced inside the vein and the inferior edge of the lymphatics introduced into the vein lumen acted as valves to avoid backflow of blood into the lymphatics (Campisi et al., 2007), thus preventing the occurrence of thrombosis. In fact, lymphatic microsurgery techniques have been shown to be effective in the treatment of peripheral lymphedema (Campisi et al., 2007). To perform lymphatic-venous microanastomosis, however, the axillary reverse mapping lymphatics must be visible and preserved as much as possible during axillary lymph node dissection, while maintaining oncological radicality.

On the other hand, postmastectomy radiotherapy is currently accepted as a standard adjuvant treatment in patients with more than 4 positive axillary nodes (Noguchi et al., 2002; Recht et al., 2001). According to the Guidelines of the American Society of Clinical Oncology (Recht et al., 2001), the chest wall as well as the supraclavicular region should be irradiated, whereas full axillary radiotherapy should not be performed routinely in patients undergoing axillary lymph node dissection. In postmastectomy radiotherapy, the lymphatic-venous microanastomosis in the axilla can be exposed to non-negligible irradiation as tangents with chest wall irradiation. It is well known that arm lymphedema can be caused by scar formation from surgery and/or radiation therapy. Therefore, long-term follow-up studies are required before we can conclude that this microsurgical technique is effective for prevention of arm lymphedema even after postmastectomy radiotherapy.

\section{Conclusions}

The axillary reverse mapping procedure is not completely accurate in differentiating between the arm and breast lymphatic pathways. The ARM node is involved with metastatic foci in some patients with extensive axillary lymph node metastasis. Moreover, the sentinel lymph node draining the breast is the same node as the axillary reverse mapping node draining the upper extremity in a minority of patients. It is oncologically unacceptable to preserve a metastatic axillary reverse mapping node in axillary lymph node dissection or converged sentinel lymph node - axillary reverse mapping node in sentinel lymph node biopsy. In patients with a positive sentinel lymph node who subsequently underwent axillary lymph node dissection, however, remaining axillary reverse mapping nodes are tumor-free as far as it is not the same as positive sentinel lymph node. Therefore, it may be oncologically safe to spare the axillary reverse mapping nodes during axillary lymph node dissection only in patients with clinically uninvolved nodes. Further studies are needed before this technology can be accepted as a standard procedure in the surgical management of breast cancer. On the other hand, it is not always possible to preserve ARM nodes and/or lymphatics during axillary lymph node dissection. Therefore, microsurgical lymphatic-venous anastomosis may be effective for prevention of arm lymphedema in patients who underwent axillary lymph node dissection with removal of axillary reverse mapping nodes. However, long-term followup studies are required before we can conclude that it is effective for prevention of arm lymphedema even after postmastectomy radiotherapy.

\section{References}

Albertini JJ. Lyman GH, Cox C, Yeatman T, Balducci L, Ku N, Shivers S, Berman C, Wells K, Rapaport D, Shons A, Horton J, Greenberg H, Nicosia S, Clark R, Cantor A, \& 
Reintgen DS. (1996). Lymphatic mapping and sentinel node biopsy in the patients with breast cancer. J Am Med Assoc Vol. 276, No. 22, pp. 1818-1822, ISSN 0098-7484.

Bedrosian I, Babiera GV, Mittendorf EA, Kuerer HM, Pantoja L, Hunt KK, Krishnamurthy S, \& Meric-Bernstam FM (2010). A phase I study to assess the feasibility and oncologic safety of axillary reverse mapping in breast cancer patients. Cancer Vol. 116, No. 11, pp. 2543-2548, ISSN 0008-543X.

Blanchard DK, Donohue JH, Reynolds C, \& Grant CS (2003). Relapse and morbidity in patients undergoing sentinel lymph node biopsy alone or with axillary dissection for breast cancer, Arch Surg Vol. 138, No. 5, pp. 482-488, ISSN 0344-8444.

Boneti C, Korourian S, Bland K, Cox K, Adkins LL, Henry-Tillman RS, \& Klimberg VS (2008). Axillary reverse mapping: mapping and preserving arm lymphatics may be important in preventing lymphedema during sentinel lymph node biopsy. J Am Coll Surg Vol. 206, No. 5, pp. 1038-1044, ISSN 1072-7515.

Boneti C, Korourian S, Diaz Z, Santiago C, Mumford S, Adkins L, \& Klimberg VS (2009). Scientific Impact Award: Axillary reverse mapping (ARM) to identify and protect lymphatics draining the arm during axillary lymphadenectomy. Am J Surg Vol. 198, No. 4, pp. 482-487, ISSN 0002-9610.

Borgstein PJ, Meijer S, Pijers RJ, \& van Diest PJ (2000). Functional lymphatic anatomy for sentinel node biopsy in breast cancer: echoes from the past and the periareolar blue method. Ann Surg Vol. 232, No. 1, pp. 81-89, ISSN 0003-4932.

Britton TB, Solanki CK, Pinder SE, Mortimer PS, Peters AM, \& Purushotham AD (2009). Lymphatic drainage pathways of the breast and the upper limb. Nucl Med Comm Vol. 30, No. 6, pp. 427-430, ISSN 0143-3636.

Campisi C, Eretta C, Pertile D, Da Rin E, Campisi C, Maccio A, Campisi M, Accogli S, Bellini C, Boniolo E, \& Boccardo F (2007). Microsurgery for treatment of peripheral lymphedema: long-term outcome and future perspectives. Microsurgery Vol. 27, No. 4, pp. 333-338, ISSN 0738-1085.

Casabona F, Bogliolo S, Ferrero S, Boccardo F, \& Campisi C (2008). Axillary reverse mapping in breast cancer: A new microsurgical lymphatic-venous procedure in the prevention of arm lymphedema. Ann Surg Oncol Vol. 15, No. 11, pp. 3318-3319, ISSN 1068-9265.

Casabona F, Bogliolo S, Valenzano Menada M, Sala P, Villa G, \& Ferrero S (2009). Feasibility of axillary reverse mapping during sentinel lymph node biopsy in breast cancer patients. Ann Surg Oncol Vol. 16, No. 9, pp. 2459-2463, ISSN 1068-9265.

Celebioglu F, Perbeck L, Frisell J, Grondal E, Svensson L, \& Danielsson R (2007). Lymph drainage studied by lymphoscintigraphy in the arms after sentinel node biopsy compared with axillary lymph node dissection following conservative breast cancer surgery. Acta Radiol Vol. 48, No. 5, pp.488-495, ISSN 0001-6926.

Grant RN, Tabah EJ, \& Adair FF (1953). The surgical significance of the subareolar lymph plexus in cancer of the breast. Surgery Vol. 33, No. 1, pp. 71-78, ISSN 0039-6060.

Haid A, Koberle-Wuhrer R, Knauer M, Burtscher J, Fritzsche H, Peschina W, Jasarevic Z, Ammann M, Hergan K, Sturn H, \& Zimmermann G (2002). Morbidity of breast cancer patients following complete axillary dissection or sentinel node biopsy only: a comparative evaluation. Breast Cancer Res Treat Vol. 73, No. 1, pp. 31-36, ISSN 0167-6806. 
Kang SH, Choi JE, Jeon YS, Lee SJ, \& Bae YK (2009). Preservation of lymphatic drainage from arm in breast cancer surgery: Is it safe? Cancer Research Vol. 69, No. Suppl 2, pp. 87s, ISSN 0576-6656.

Khan SA \& Lurie RH (2009). Axillary reverse maping to prevent lymphedema after breast cancer surgery: Defining the limits of the concept. J Clin Oncol Vol. 27, No. 33, pp.5494-5496, ISSN 0732-183X.

Klimberg VS (2008). A new concept toward the prevention of lymphedema: Axillary reverse maping. J Surg Oncol Vol. 97, No. 7, pp.563-564, ISSN 0022-4790.

Klimberg VS (2010). Chapter 14 Axillary reverse mapping, Atlas of Breast Surgical Techniques, Klimberg (ed), pp174-181, Surgical Techniques Atlas Series, Townsend Jr CM, Evers BM, eds., Saunders Co., ISBN 978-1-4160-4691-2, Philadelphia, PA, USA.

Kodama H, Mise K \& Kan N (2010). Lower axillary dissection for early breast cancer. J Jap Surg Assoc Vol. 71, No. 12. pp. 3031-3038 (in Japanese with English abstract), ISSN 1345-2843.

Leidenius M, Leivonen M, Vironen J, \& von Smitten K (2005). The consequences of longtime arm morbidity in node-negative breast cancer patients with sentinel node biopsy or axillary clearance. J Surg Oncol Vol. 92, No. 1, pp 23-31, ISSN 0022-4790

Lucci A, McCall LM, Beitsch PD, Whitworth PW, Reintgen DS, Blumencranz PW, Leitch AM, Saha S, Hunt KK, \& Giuliano AE (2007). Surgical complications associated with sentinel lymph node dissection (SLND) plus axillary lymph node dissection compared with SLND alone in the American College of Surgeons Oncology Group Trial Z0011. J Clin Oncol Vol. 25, No. 24, pp.3657-3663, ISSN 0732-183X.

Mansel RE, Fallowfield L, Kissin M, Goyal A, Newcombe RG, Dixon JM, Yiangou C, Horgan K, Bundred N, Monypenny I, England D, Sibbering M, Abdullah TI, Barr L, Chetty U, Sinnett DH, Fleissig A, Clarke D, \& Ell PJ (2006). Randomized multicenter trial of sentinel node biopsy versus standard axillary treatment in operable breast cancer: The ALMANAC Trial. JNCI Vol. 98, No. 9, pp. 599-609, ISSN 0027-8874.

McLaughlin SA, Wright MJ, Morris KT, Giron GL, Sampson MR, Brockway JP, Hurley KE, Riedel ER, \& Van Zee KJ (2008). Prevalence of lymphedema in women with breast cancer 5 years after sentinel lymph node biopsy or axillary dissection: objective measurements. J Clin Oncol Vol. 26, No. 32, pp. 5313-5319, ISSN 0732-183X.

Noguchi M, Miwa K, Michigishi T, Yokoyama K, Nishijima H, Takanaka T, Kawashima H, Nakamura S, \& Nonomura A (1997). The role of axillary lymph node dissection in breast cancer management. Breast Cancer Vol. 4, No. 3, pp. 143-153, ISSN 1340-6868.

Noguchi M, Motomura K, Imoto S, Miyauchi M, Sato K, Iwata H, Ohta M, Kurosumi M, \& Tsugawa K (2000). A multicenter validation study of sentinel lymph node biopsy by the Japanese Breast Cancer Society. Breast Cancer Res Treat Vol. 63, No. 1, pp. 3140, ISSN 0167-6806.

Noguchi M (2002). Does regional treatment improve the survival in patients with operable breast cancer? Breast Cancer Res Treat Vol. 76, No. 3, pp. 269-282, ISSN 0167-6806.

Noguchi M, Inokuchi M, \& Zen Y (2009). Complement of peritumoral and subareolar injection in breast cancer sentinel lymph node biopsy. J Surg Oncol Vol. 100, No. 2, pp.100-105, ISSN 0022-4790.

Noguchi M (2010a). Axillary reverse mapping for preventing lymphedema in the axillary lymph node dissection and/or sentinel lymph node biopsy (Editorial). Breast Cancer Vol. 17, No. 3, pp. 155-157. ISSN 1340-6868. 
Noguchi M, Yokoi M, \& Nakano Y (2010b). Axillary reverse mapping with indocyanine fluorescence imaging in patients with breast cancer. J Surg Oncol Vol. 101, No. 3, pp.217-221, ISSN 0022-4790.

Noguchi M (2010c). Axillary reverse mapping for breast cancer. Breast Cancer Res Treat Vol. 119, No. 3, pp. 529-535, ISSN 0167-6806.

Nos C, Lesieur B, Clough KB, \& Lecuru F (2007). Blue dye injection in the arm in order to conserve the lymphatic drainage of the arm in breast cancer patients requiring an axillary dissection. Ann Surg Oncol Vol. 14, No. 9, pp. 2490-2496, ISSN 1068-9265.

Nos C, Kaufmann G, Clough KB, Collignon M-A, Zerbib E, Cusumano P, \& Lecuru F (2008). Combined axillary mapping (ARM) technique for breast cancer patients requiring axillary dissection. Ann Surg Oncol Vol. 15, No. 9, pp. 2550-2555, ISSN 1068-9265.

Ponzone R, Mininanni P, Cassina E, \& Sismondi P (2008). Axillary reverse mapping in breast cancer: can we spare what we find? Ann Surg Oncol Vol. 15, No. 1, pp.390-391, ISSN 1068-9265.

Ponzone R, Cont NT, Maggiorotto F, Cassina E, Mininanni P, Biglia N, \& Sismondi P (2009) Extensive nodal disease may impair axillary reverse mapping in patients with breast cancer. J Clin Oncol Vol. 27, No. 33, pp.5547-5551, ISSN 0732-183X.

Recht A, Edge SB, Solin LJ, Robinson DS, Estabrook A, Fine RE, Fleming GF, Formenti S, Hudis C, Kirshner JJ, Krause DA, Kuske RR, Langer AS, Sledge GW Jr, Whelan TJ, \& Pfister DG (2001). Postmastectomy radiotherapy: clinical practice guidelines of the American Society of Clinical Oncology. J Clin Oncol Vol. 19, No. 5, pp. 15391569, ISSN 0732-183X.

Ronka R, von Smitten K, Tasmuth T, \& Leidenius M (2005). One-year morbidity after sentinel node biopsy and breast surgery. Breast Vol. 14, No. 1, pp. :28-36, ISSN 0960-9776.

Rouviere H (1932) Anatomie des Lymphatiques de l'Homme. Paris: Masson.

Sakorafas GH, Peros G, Cataliotti L, \& Vlastos G (2006). Lymphedema following axillary lymph node dissection for breast cancer. Surg Oncol Vol. 15, No. 3, pp. 153-165, ISSN 0960-7404.

Sappey MPC (1874). Anatomie, Physiologie, Pathologie des vaisseaux Lymphatiques consideres chez L' homme at les Vertebres. Paris: A. Delahaye and E. Lecrosnier.

Schijven MP, Vingerhoets AJ, Rutten HJ, Nieuwenhuijzen GA, Roumen RM, van Bussel ME, \& Voogd AC (2003). Comparison of morbidity between axillary lymph node dissection and sentinel node biopsy. Eur J Surg Oncol Vol. 29, No. 4, pp. 341-350, ISSN 0748-7983.

Schrenk P, Rieger R, Shamiyeh A, \& Wayand W (2000). Morbidity following sentinel lymph node biopsy versus axillary lymph node dissection for patients with breast carcinoma. Cancer Vol. 88, No. 3, pp. 608-614, ISSN 0008-543X.

Sener SF, Winchester DJ, Martz CH, Feldman JL, Cavanaugh JA, Winchester DP, Weigel B, Bonnefoi K, Kirby K, \& Morehead C (2001). Lymphedema after sentinel lymphadenectomy for breast carcinoma. Cancer Vol. 92, No. 4, pp. 748-752, ISSN 0008-543X.

Spratt JS (1979). Anatomy of the breast. Major Prob Clin Vol. 5, pp. 1-13, ISSN 0025-1062.

Suami H, Taylor GI, \& Pan WR (2007a). The lymphatic territories of the upper limb: anatomical study and clinical implications. Plast Reconstr Surg Vol. 119, No. 6, pp. 1813-1822, ISSN 0032-1052. 
Suami H, Pan WR, \& Taylor GI (2007b). Changes in the lymph structure of the upper limb after axillary dissection: radiographic and anatomical study in a human cadaver. Plast Reconstr Surg Vol. 120, No. 4, pp. 982-991, ISSN 0032-1052.

Suami H, O' Neill JK, Pan WR, \& Taylor GI (2008) Superficial lymphatic system of the upper torso: preliminary radiographic results in human cadavers. Plast Reconstr Surg Vol. 121, No. 4, pp. 1231-1239, ISSN 0032-1052.

Swenson KK, Nissen MJ, Ceronsky C, Swenson L, Lee MW, \& Tuttle TM (2002). Comparison of side effects between sentinel lymph node and axillary lymph node dissection for breast cancer. Ann Surg Oncol Vol. 9, No. 8, pp. 745-753, ISSN 1068-9265.

Tanis PJ, Nieweg OE, Valdes Olmos RA, \& Kroon BB (2001). Anatomy and physiology of lymphatic drainage of the breast from the perspective of sentinel node biopsy. J Am Coll Surg Vol. 192, No. 3, pp. 399-409, ISSN 1072-7515.

Thompson M, Korourian S, Henry-Tillman R, Adkins L, Mumford S, Westbrook KC, \& Klimberg VS (2007). Axillary reverse mapping (ARM): a new concept to identify and enhance lymphatic preservation. Ann Surg Oncol Vol. 14, No. 6, pp. 1890-1895, ISSN 1068-9265.

Turner-Warwick RT (1959). The lymphatics of the breast. Br J Surg Vol. 46, pp. 574-582, ISSN 0007-1323.

Wilke LG, McCall LM, Posther KE, Whitworth PW, Reintgen DS, Leitch AM, Gabram SG, Lucci A, Cox CE, Hunt KK, Herndon JE II, \& Giuliano AE (2006). Surgical complications associated with sentinel lymph node biopsy: results from a prospective international cooperative group trial. Ann Surg Oncol Vol. 13, No. 4, pp. 491-500, ISSN 1068-9265.

Yokoi M, Noguchi M, Nakano Y, Ohno Y, \& Kosaka T (n.d.). Axillary reverse mapping using fluorescence imaging system in breast cancer. Breast Cancer Res Treat (submitted)., ISSN 0167-6806. 


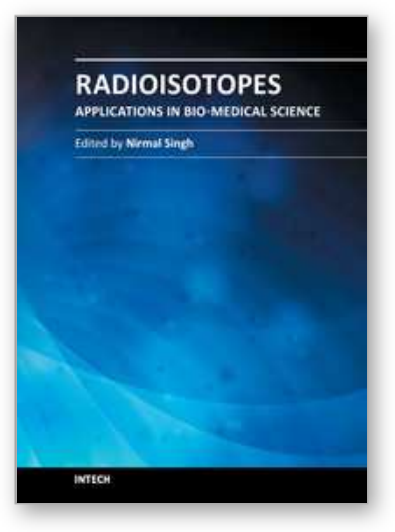

\author{
Radioisotopes - Applications in Bio-Medical Science \\ Edited by Prof. Nirmal Singh
}

ISBN 978-953-307-748-2

Hard cover, 320 pages

Publisher InTech

Published online 21, November, 2011

Published in print edition November, 2011

The book Radioisotopes - Applications in Bio-Medical Science contains two sections: Radioisotopes and Radiations in Bioscience and Radioisotopes and Radiology in Medical Science. Section I includes chapters on medical radioisotope production, radio-labeled nano-particles, radioisotopes and nano-medicine, use of radiations in insects, drug research, medical radioisotopes and use of radioisotopes in interdisciplinary fields etc. In Section II, chapters related to production of metal PET (positron emission tomography) radioisotopes, 3-dimensional and CT (computed tomography) scan, SS nuclear medicine in imaging, cancer diagnose and treatments have been included. The subject matter will by highly useful to the medical and paramedical staff in hospitals, as well as researchers and scholars in the field of nuclear medicine medical physics and nuclear biochemistry etc.

\title{
How to reference
}

In order to correctly reference this scholarly work, feel free to copy and paste the following:

Masakuni Noguchi, Miki Yokoi, Yasuharu Nakano, Yukako Ohno and Takeo Kosaka (2011). Axillary Reverse Mapping in Breast Cancer, Radioisotopes - Applications in Bio-Medical Science, Prof. Nirmal Singh (Ed.), ISBN: 978-953-307-748-2, InTech, Available from: http://www.intechopen.com/books/radioisotopesapplications-in-bio-medical-science/axillary-reverse-mapping-in-breast-cancer

\section{INTECH}

open science | open minds

\author{
InTech Europe \\ University Campus STeP Ri \\ Slavka Krautzeka 83/A \\ 51000 Rijeka, Croatia \\ Phone: +385 (51) 770447 \\ Fax: +385 (51) 686166 \\ www.intechopen.com
}

\author{
InTech China \\ Unit 405, Office Block, Hotel Equatorial Shanghai \\ No.65, Yan An Road (West), Shanghai, 200040, China \\ 中国上海市延安西路65号上海国际贵都大饭店办公楼405单元 \\ Phone: +86-21-62489820 \\ Fax: +86-21-62489821
}


(C) 2011 The Author(s). Licensee IntechOpen. This is an open access article distributed under the terms of the Creative Commons Attribution 3.0 License, which permits unrestricted use, distribution, and reproduction in any medium, provided the original work is properly cited. 